\title{
KESESUAIAN KAWASAN UNTUK PENGEMBANGAN EKOWISATA HUTAN MANGROVE KUALA LANGSA
}

\author{
Land Suitability for Kuala Langsa Mangrove Ecotourism Development \\ Kurnia Tari , Iswahyudi, Dolly S. Siregar \\ Program Studi Agroteknologi, Fakultas Pertanian, Universitas Samudra \\ JI, Meurandeh, Langsa Lama, Kota Langsa, Aceh 24354 \\ *Email : kurniatari1997@gmail.com
}

Direvisi: 07/07/2020, Diterbitkan: 01/08/2020

\begin{abstract}
Langsa City is mostly in the form of land and coastal areas, especially the Kuala Langsa area which has the potential to be developed into an ecotourism development area because the mangrove ecosystem is still natural and preserved. This study aims to determine the level of land suitability for the development of mangrove forest ecotourism in Kuala Langsa. Primary data in the form of mangrove density, mangrove thickness, types of mangroves, tides, and biota objects were obtained through observation at 6 observation locations using Purposive sampling and Line transect point methods, while secondary data included geographical conditions, and tidal data obtained through literature studies. Vegetation data were analyzed by calculating plant species density and tourism suitability analyzed using tourism suitability index (IKW). Mangrove species found at the study site included, Bruguiera gymnorrhiza, Ceriops tagal, Rhizophora apiculata, Rhizophora mucronata, Sonneratia caseolaris and Xylocarpus granatum. The results showed that the $I K W$ value of $60 \%$ included in the $S_{2}$ category (as appropriate). The limiting factor is the density of mangroves which only have a value of 8 with the $S_{3}$ conformity category (as conditional). With the limiting factor is the density of mangroves which only have a value of 4 with the suitability category $S_{3}$ (not suitable). As for suggestions that can be given to the manager of Kuala Langsa mangrove forest Ecotourism so that the existence of Ecotourism can be sustainable is the need for Pentahelix Synergy in the management of the ecotourism.
\end{abstract}

Keywords; Ecotourism, Tourism suitability index, Mangrove

\begin{abstract}
ABSTRAK
Kota Langsa sebagian besar wilayahnya berupa daratan dan pesisir khususnya kawasan Kuala Langsa yang memiliki potensi daya tarik untuk dikembangkan menjadi daerah pengembangan ekowisata karena kawasan ekosistem mangrove yang masih alami dan terjaga kelestariannya. Penelitian ini bertujuan untuk mengetahui tingkat kesesuaian kawasan untuk pengembangan ekowisata hutan mangrove di Kuala Langsa. Data primer berupa kerapatan mangrove, ketebalan mangrove, jenis mangrove, pasang surut, dan objek biota yang diperoleh melalui pengamatan pada 6 titik lokasi pengamatan dengan menggunakan metode Purposive sampling dan Line transek point, sedangkan data sekunder meliputi kondisi geografis, dan data pasang surut air laut diperoleh melalui studi literatur. Data vegetasi dianalisis dengan menghitung kerapatan jenis tumbuhan dan kesesuaian wisata dianalisis dengan menggunakan indeks kesesuaian wisata (IKW). Jenis mangrove yang ditemukan di lokasi penelitian meliputi, Bruguiera gymnorrhiza, Ceriops tagal, Rhizophora apiculata, Rhizophora mucronata, Sonneratia caseolaris dan Xylocarpus granatum. Hasil penelitian menunjukkan bahwa nilai IKW $60 \%$ yang termasuk dalam kategori
\end{abstract}


$\mathrm{S}_{2}$ (sesuai). Dengan faktor pembatasnya adalah kerapatan mangrove yang hanya mempunyai nilai 8 dengan kategori kesesuaian $\mathrm{S}_{3}$ (sesuai bersyarat). Adapun saran yang dapat diberikan kepada pengelola Ekowisata hutan mangrove Kuala Langsa agar keberadaan Ekowisatanya dapat berkelanjutan adalah diperlukan adanya Sinergitas Pentahelix dalam pengelolaan ekowisata tersebut.

Kata kunci: Ekowisata, Indeks kesesuaian wisata, Mangrove

\section{PENDAHULUAN}

Hutan mangrove adalah sebutan umum yang digunakan untuk menggambarkan suatu varietas komunitas pantai tropika yang didominasi oleh beberapa spesies pohon-pohon yang khas atau semak-semak yang mempunyai kemampuan untuk tumbuh di perairan payau. Jadi, ekosistem mangrove adalah dimana mangrove menjadi tempat berlangsungnya kehidupan yang memiliki hubungan timbal balik antara makhluk hidup dengan lingkungannya dan diantara makhluk hidup itu sendiri, yang terdapat di wilayah pesisir, dipengaruhi oleh pasang surut air laut, dan juga didominasi oleh spesies pohon atau semak yang khas dan mampu tumbuh pada perairan masin atau payau (Nurlailita, 2015).

Ekowisata merupakan paket perjalanan menikmati keindahan lingkungan tanpa merusak eksosistem hutan yang ada. Vegetasi hutan yang terletak melintang dari arah arus laut merupakan keindahan dan keanekaragaman vegetasi yang berbeda dari formasi hutan lainnya. (Rahim dan Baderan, 2017). Ekowisata mangrove merupakan objek wisata yang berwawasan lingkungan dimana wisata tersebut mengutamakan aspek keindahan yang alami dari hutan mangrove serta fauna yang hidup di sekitarnya tanpa harus merusak ekosistem tersebut. yang membuat wisatawan menjadi tertarik ialah disebabkan oleh hutan mangrove yang mempunyai ciri khas yang khusus dan memiliki banyak fauna dan flora yang hidup disekitarnya tersebut (Roza, dkk., 2018).

Sebagai kawasan ekowisata, Hutan mangrove Kuala Langsa menjadi pilihan obyek wisata baru karena terbatasnya obyek wisata alam di Langsa. Pemanfaatan ekosistem mangrove untuk konsep wisata (ekowisata) sejalan dengan pergeseran minat wisatawan dari old tourism yaitu wisatawan yang hanya datang melakukan wisata saja tanpa ada unsur pendidikan dan konservasi menjadi new tourism yaitu wisatawan yang datang untuk melakukan wisata yang di dalamnya ada unsur pendidikan dan konservasi. Keberadaan hutan mangrove di Kuala Langsa, Kota Langsa, Provinsi Aceh, telah memberikan dampak yang signifikan pada pertumbuhan dan perkembangan ekonomi masyarakat Kota Langsa. Hutan mangrove yang dilindungi oleh peraturan daerah atau qanun Kota Langsa tersebut, berfungsi sebagai ekosistem bagi masyarakat setempat (Hafizi, dkk. 2017)

Agar ekowisata ini dapat berkembang dan menjadi daya tarik wisata di Kota Langsa, diperlukan konsep pengelolaan yang komprehensif dan terpadu dalam pengembangannya sehingga menjamin keberlanjutan ekowisata mangrove Kuala Langsa. Untuk itu diperlukan suatu kajian untuk menilai kesesuaian lahan untuk pengembangan ekowisata hutan mangrove di Kuala Langsa. Tujuan dari penelitian ini untuk mengetahui tingkat kesesuaian lahan untuk pengembangan ekowisata hutan mangrove di Kuala Langsa.

\section{METODE}

Penelitian ini dilakukan di wilayah Ekowisata Mangrove Kuala Langsa Kota Langsa Provinsi Aceh. Waktu pelaksanaan penelitian selama 2 bulan yang dimulai dari bulan Februari sampai dengan bulan Maret 2020. Alat-alat yang digunakan terdiri atas sampan, sepatu bot, Global Positioning System (GPS), kamera, meteran jahit, tali rafia, dan alat tulis menulis. Bahan-bahan yang digunakan terdiri atas buku identifikasi (mangrove dan biota) dan panduan wawancara. Penelitian ini menggunakan metode deskriptif dengan teknik 
survei. Lokasi penelitian ditentukan secara "Purposive Sampling" yaitu lokasi yang dipilih secara langsung atau sengaja dengan alasan bahwa pada lokasi tersebut merupakan lokasi pengembangan ekowisata. Identifikasi jenis mangrove dilapangan dilakukan dengan menggunakan buku panduan identifikasi mangrove.

\section{Analisis Komposisi Jenis Mangrove}

Identifikasi jenis mangrove dilapangan dilakukan dengan menggunakan buku panduan identifikasi mangrove, jika ada yang belum diketahui dilakukan dengan cara pengambilan gambar/foto atau mengambil bagian dari ranting, bunga, dan daunnya kemudian diidentifikasi berdasarkan buku identifikasi mangrove.

\section{Analisis Struktur Vegetasi Mangrove}

Pengambilan sampling dilakukan menggunakan metode "Line Transect Point" yaitu metode pengamatan untuk mewakili populasi pada suatu ekosistem. Di lokasi pengamatan dibuat 6 transek, yaitu : pada setiap titik pengamatan dibuat garis tegak lurus dari arah darat kearah laut sepanjang $100 \mathrm{~m}$. Pada jalur-jalur yang telah dibentuk dibuat 3 petak plot pengambilan sampel berbentuk bujur sangkar dengan ukuran $10 \mathrm{~m} \times 10 \mathrm{~m}$ (tingkat pohon), $5 \mathrm{~m} \times 5 \mathrm{~m}$ (tingkat pancang) dan $2 \mathrm{~m} \times 2 \mathrm{~m}$ (tingkat semai). Jarak antar plot dalam satu transek 20 meter. Pengamatan yang dilakukan pada setiap petak plot yaitu; mengidentifkasi jenis mangrove, menghitung jumlah individu setiap jenis, dan mengukur lingkar diameter batang yang dilakukan setinggi dada $(\mathrm{DBH}=$ Diameter Breast High) dari permukaan tanah. Bagi pohon yang mempunyai akar banir dan akar tunjang, pengukuran dilakukan tepat di atas banir dan pangkal tunjang.

Untuk menganalisis suatu vegetasi diperlukan data dari lapangan untuk menghitung kerapatan, frekuensi, dominansi, dan indeks nilai penting yang digunakan untuk mengetahui komposisi jenis dan struktur vegetasi dalam suatu ekosistem. Menurut Kusmana, (1997) data yang diperoleh dari hasil pengukuran di lapangan dihitung untuk menentukan Indeks Nilai Penting (INP) yang dihitung dengan cara :

a. Untuk tingkat pohon INP $(\%)=K R+D R+F R$

b. Untuk tingkat semai dan pancang: INP $(\%)=(K R)+(F R)$

dimana ; Kerapatan relatif $(K R)$, frekuensi suatu jenis $(F)$, frekuensi relatif $(F R)$, dominasi suatu jenis (D), dominansi relatif (DR) ; dihitung dengan rumus sebagai berikut :

a. Kerapatan suatu jenis $(\mathrm{K})$, dihitung dengan rumus :

$$
K\left(\frac{\text { batang }}{h a}\right)=\frac{\text { Jumlah individu suatu Jenis }}{\text { Luas petak contoh }}
$$

a. Kerapatan relatif $(K R)$ suatu jenis, dihitung dengan rumus :

$$
K R=\frac{\text { Kerapatan suatu Jenis }}{\text { Kerapatan seluruh jenis }} X 100 \%
$$

b. Frekuensi $(F)$ suatu jenis, dihitung dengan rumus :

$$
F=\frac{\text { Jumlah petak ditemukan suatu Jenis }}{\text { Jumlah seluruh petak contoh }}
$$

c. Frekuensi relatif (FR) suatu jenis, dihitung dengan rumus :

$$
F R=\frac{\text { Frekuensi suatu Jenis }}{\text { Frekuensi seluruh jenis }} X 100 \%
$$

d. Dominasi (D) suatu jenis, dihitung dengan rumus :

$$
D\left(m^{2} / h a\right)=\frac{\text { Luas bidang dasar suatu jenis }}{\text { Luas petak contoh }} \text {..... }
$$

Untuk mendapatkan nilai luas bidang dasar (LBD) pada perhitungan dominansi menggunakan rumus sebagai berikut : $\operatorname{LBD}\left(m^{2}\right)=1 / 4 \pi(d)^{2}$

e. Dominasi relatif (DR) suatu jenis, dihitung dengan rumus : 


$$
D R=\frac{\text { Dominasi suatu Jenis }}{\text { Dominasi seluruh jenis }} X 100 \%
$$

\section{Analisis Ketebalan Mangrove}

Ketebalan mangrove diukur dengan cara kombinasi antara analisis citra satelit dan pengukuran langsung di lapangan dengan menggunakan roll meter di setiap stasiun diukur secara tegak lurus dari arah darat ke arah laut.

\section{Analisis Pasang Surut}

Untuk analisis pasang surut lokasi penelitian digunakan data yang di peroleh dari "tides4fishing.com". Adapun data yang dipakai adalah data bulan Februari 2020 (Tanggal 129 Februari 2020). Kemudian data ini dihitung dengan rumus dibawah ini.

$$
\mathrm{A}=\text { pasang tertinggi }- \text { surut terendah }
$$

\section{Analisis Objek Biota}

Objek Biota diamati secara langsung didalam transek kuadrat atau petak plot yang ditangkap mengunakan serok ikan. Biota yang ditemukan kemudian dilakukan pengambilan gambar/foto, lalu di identifikasi menggunakan buku identifikasi biota.

\section{Analisis Kesesuaian Wisata Mangrove}

Tingkat kesesuaian wisata mangrove dianalisis menggunakan indeks kesesuaian wisata (IKW) dengan rumus sebagai berikut (Yulianda, 2007 dalam Latupapua, dkk. 2019).

$$
\mathbf{I K W}=\sum\left[\frac{N i}{N_{\text {maks }}}\right] \times 100 \%
$$

$I K W=$ Indeks kesesuaian wisata

$N_{i} \quad=$ Nilai parameter ke-i (Bobot $\square$ Skor)

$N_{\text {maks }} \quad=$ Nilai maksimum dari suatu kategori wisata (80)

Nilai dari indeks kesesuaian wisata yang didapat kemudian disesuaikan dengan kategori berikut:

1. $\mathrm{S} 1=$ Sangat Sesuai, dengan IKW $>75-100 \%$

2. $\mathrm{S} 2=$ Sesuai, dengan IKW $>50-75 \%$

3. S3 $=$ Sesuai Bersyarat, dengan nilai $>25-50 \%$

4. $\mathrm{N}=$ Tidak Sesuai, dengan nilai $>25 \%$

Penilaian tingkat kesesuaian mangrove dilakukan dengan menggunakan matrik kesesuaian area untuk wisata pantai kategori wisata mangrove (Tabel 1). Penilaian dilakukan berdasarkan pembobotan dan nilai yang ditunjukkan dengan besarnya skor, yang selanjutnya dilakukan penggabungan beberapa variabel perbedaan nilai antara kelas untuk menetapkan klasifikasi kesesuaian kawasan mangrove Kuala Langsa (Tabel 2). 
Tabel 3. Matriks Kesesuaian Area untuk Wisata Pantai Kategori Wisata Mangrove.

Table 3. Matrix of Area Suitability for Beach Tourism Mangrove Tourism Category.

\begin{tabular}{|c|c|c|c|c|c|c|c|c|c|c|}
\hline No & Parameter & Bobot & $\begin{array}{c}\text { Kategori } \\
\text { S1 }\end{array}$ & Skol & $\begin{array}{c}\text { Kategori } \\
\text { S2 }\end{array}$ & Skor & $\begin{array}{c}\text { Kategori } \\
\text { S3 }\end{array}$ & Skor & $\begin{array}{c}\text { Kategori } \\
\mathrm{N}\end{array}$ & Skor \\
\hline 1 & $\begin{array}{c}\text { Ketebalanm } \\
\text { angrove }(\mathrm{m}) \\
\text { Kerapatan }\end{array}$ & 5 & $>500$ & 4 & $>200-500$ & 3 & $50-200$ & 2 & $<50$ & 1 \\
\hline 2 & $\begin{array}{l}\text { Mangrove } \\
\left(100 \mathrm{~m}^{2}\right)\end{array}$ & 4 & $>15-25$ & 4 & $>10-15$ & 3 & $5-10$ & 2 & $<5$ & 1 \\
\hline 3 & $\begin{array}{l}\text { Jenis } \\
\text { Mangrove }\end{array}$ & 4 & $>5$ & 4 & $3-5$ & 3 & $1-2$ & 2 & 0 & 1 \\
\hline 4 & $\begin{array}{l}\text { Pasang } \\
\text { Surut }\end{array}$ & 3 & $0-1 \mathrm{~m}$ & 4 & $>1-2 \mathrm{~m}$ & 3 & $>2-5 \mathrm{~m}$ & 2 & $<5 \mathrm{~m}$ & 1 \\
\hline 5 & Objek Biota & 3 & $\begin{array}{c}\text { lkan, } \\
\text { udang, } \\
\text { kepiting, } \\
\text { molusca, } \\
\text { reptil, } \\
\text { Burung }\end{array}$ & 4 & $\begin{array}{c}\text { Ikan, } \\
\text { udang, } \\
\text { kepiting, } \\
\text { molusca }\end{array}$ & 3 & $\begin{array}{l}\text { lkan, } \\
\text { molusca }\end{array}$ & 2 & $\begin{array}{c}\text { Salah } \\
\text { satu biota } \\
\text { air }\end{array}$ & 1 \\
\hline
\end{tabular}

Sumber : Yulianda (2007) dalam Latupapua, dkk., 2019

Tabel 2. Indeks Kesesuaian Wisata

Table 2. Travel Conformance Index

\begin{tabular}{ccc}
\hline No & \multicolumn{1}{c}{ Kategori } & Nilai Interval Kesesuaian \\
\hline & & \\
1 & S1 (Sangat Sesuai) & $\mathrm{IKW}>75 \%-100 \%$ \\
2 & S2 (Sesuai) & $\mathrm{KIW}>50 \%-75 \%$ \\
3 & S3 (Sesuai Bersyarat) & $>25 \%-50 \%$ \\
4 & $\mathrm{~N}$ (Tidak Sesuai) & $>25 \%$ \\
\hline \multicolumn{3}{l}{ Sumber : Yulianda (2007) dalam Latupapua, dkk., (2019). }
\end{tabular}

\section{HASIL DAN PEMBAHASAN}

\section{Komposisi Jenis Mangrove}

Berdasarkan hasil identifikasi yang dilakukan terdapat 6 jenis tumbuhan mangrove di lokasi penelitian (Tabel 3). Berdasarkan pengelompokan mangrove oleh Kusmana, dkk. (2005), di lokasi penelitian terdapat dua kelompok mangrove, yaitu : kelompok mangrove mayor terdiri dari 5 jenis (famili Rhizophoraceae dan Sonneratiaceae) dan kelompok mangrove minor yang terdiri dari 1 jenis (famili Meliaceae).

Secara umum ekosistem mangrove di Ekowisata Hutan Mangrove Kuala Langsa dapat dibagi ke tiga zona, yaitu: Zona Protaksimal (garis pantai), Zona Middle (tengah) dan Zona Distal (belakang). Jenis mangrove yang ditemukan di Zona Protaksimal adalah Rhizopora mucronata, di Zona Middle ditemukan jenis Rhizopora apiculata, Brugeria gymnorrhiza, Ceriops tagal, dan Sonneratia caseolaris. Adapun dizona Distal ditemukan jenis Xylocarpus granatum. 
Tabel 3. Jenis-jenis Tumbuhan Mangrove yang Dijumpai di Lokasi Penelitian Table 3. Types of Mangrove Plants Found at Research Sites

\begin{tabular}{llll}
\hline \multirow{2}{*}{ No Kelompok } & \multirow{2}{*}{ Famili } & Jenis \\
\cline { 3 - 4 } 1. Mangrove Sejati & Rhizophoraceae & Perta Lokal & Nama Ilmiah \\
Mayor & & Teunga & Bruguiera gymnorrhiza \\
& & Bangka Minyeuk & Rhizophora apiculata \\
& & Bangka U & Rhizophora mucronata \\
& Sonneratiaceae & Bereumbang & Sonneratia caseolaris \\
2. Mangrove Minor & Meliaceae & Nyireh & Xylocarpus granatum \\
\hline
\end{tabular}

Sumber: Data Primer (2020)

Hasil penelitian Siregar (2013) dan Zurba (2017), menyatakan bahwa di Kuala Langsa dijumpai 7 jenis mangrove, adapun hasil penelitian Iswahyudi (2019), di Hutan Mangrove Kota Langsa dijumpai 19 jenis mangrove. Hasil penelitian Nurlailita (2015), pada kondisi hutan mangrove yang berbeda di Kecamatan Rantau Selamat dan Kecamatan Birem Bayeun Kabupaten Aceh Timur yang hutan mangrovenya menyambung dengan hutan mangrove di Kota Langsa dijumpai 10 jenis mangrove.

Banyaknya jenis mangrove di suatu lokasi dapat menunjang keberagaman biota yang berasosiasi serta menjadi pilihan yang akan digemari oleh para wisatawan, karena dapat menikmati alam yang indah, udara yang sejuk serta dapat menambah wawasan tentang lingkungan hidup dan pentingnya ekosistem mangrove dalam struktur ekosistem pesisir (Sadik, dkk. 2017). Susi, dkk. (2018) menambahkan bahwa keberagaman jenis mangrove yang ada di suatu kawasan dapat menunjang aktifitas pengelolaan suatu kawasan wisata dan menambah daya tarik pengunjung.

\section{Kerapatan Jenis Mangrove}

Hasil analisis struktur vegetasi mangrove di Kuala Langsa dapat dilihat pada Tabel 4. Berdasarkan tingkat pertumbuhannya, Jenis Rhizopora apiculata mendominasi pada seluruh tingkat pertumbuhan mangrove di lokasi penelitian. 
Tabel 4. Hasil Analisis Struktur Vegetasi Mangrove Tingkat Semai, Pancang dan Pohon di Lokasi Penelitian

Table 4. Results of Analysis of Structure of Mangrove Vegetation at Seed, Stake and Tree Levels at the Research Location

\begin{tabular}{|c|c|c|c|c|c|c|c|c|}
\hline No & Nama Jenis & $\begin{array}{c}\mathrm{K} \\
\text { Individu/ha }\end{array}$ & $\begin{array}{l}\mathrm{KR} \\
(\%) \\
\end{array}$ & $F$ & $\begin{array}{l}\text { FR } \\
(\%)\end{array}$ & D & $\begin{array}{l}\text { DR } \\
(\%)\end{array}$ & $\begin{array}{l}\text { INP } \\
(\%)\end{array}$ \\
\hline \multicolumn{9}{|c|}{ Tingkat Semai } \\
\hline 1 & $\begin{array}{c}\text { Rhizopora } \\
\text { apiculata }\end{array}$ & 13888,89 & 100 & 5,56 & 100 & - & - & 200 \\
\hline Tino & $\begin{array}{l}\text { Total } \\
\text { Pancang }\end{array}$ & $13.888,89$ & 100 & 5,56 & 100 & - & - & 200 \\
\hline 1 & $\begin{array}{l}\text { Rhizopora } \\
\text { apiculata }\end{array}$ & $2.133,33$ & $\begin{array}{c}74,4 \\
2\end{array}$ & 0,72 & 56,52 & - & - & 130,94 \\
\hline 2 & $\begin{array}{l}\text { Rhizopora } \\
\text { mucronata }\end{array}$ & 44,44 & 1,6 & 0,06 & 4,35 & - & - & 5,89 \\
\hline 3 & Ceriops tagal & 244,44 & 8,5 & 0,22 & 17,39 & - & - & 25,91 \\
\hline 4 & $\begin{array}{l}\text { Xylocarpus } \\
\text { granatum }\end{array}$ & 44,44 & 1,6 & 0,06 & 4,35 & - & - & 5,89 \\
\hline 5 & $\begin{array}{c}\text { Brugeria } \\
\text { gymnorhiza }\end{array}$ & 400,00 & 14,0 & 0,22 & 17,39 & - & - & 31,34 \\
\hline Ting & $\begin{array}{l}\text { Total } \\
\text { Pohon }\end{array}$ & $2.866,67$ & 100 & 1,00 & 100 & - & - & 200 \\
\hline 1 & $\begin{array}{l}\text { Rhizopora } \\
\text { apiculata }\end{array}$ & 533,33 & $\begin{array}{c}75,0 \\
0\end{array}$ & 0,78 & 53,85 & 2087,52 & $\begin{array}{c}57,9 \\
3\end{array}$ & 186,78 \\
\hline 2 & $\begin{array}{l}\text { Sonneratia } \\
\text { caseolari }\end{array}$ & 22,22 & 3,13 & 0,11 & 7,69 & 229,42 & 6,37 & 17,18 \\
\hline 3 & Ceriops tagal & 122,22 & $\begin{array}{c}17,1 \\
9\end{array}$ & 0,39 & 26,92 & 895,13 & $\begin{array}{c}24,8 \\
4\end{array}$ & 68,95 \\
\hline 4 & $\begin{array}{l}\text { Xylocarpus } \\
\text { granatum }\end{array}$ & 22,22 & 3,13 & 0,11 & 7,69 & 237,02 & 6,58 & 17,40 \\
\hline \multirow[t]{2}{*}{5} & $\begin{array}{c}\text { Brugeria } \\
\text { gymnorhiza }\end{array}$ & 11,11 & 1,56 & 0,06 & 3,85 & 154,14 & 4,28 & 9,69 \\
\hline & Total & 711,11 & 100 & 1,44 & 100 & 3603,24 & 100 & 300 \\
\hline
\end{tabular}

Dari Tabel 4 dapat dilihat bahwa Rhizopora apiculata merupakan jenis mangrove yang memiliki tingkat kerapatan yang paling dominan pada ketiga tingkat pertumbuhan dengan tingkat kerapatan masing-masing 13.888,89 individu/ha pada tingkat semai, 2.133,33 individu/ha pada tingkat pancang dan 533,33 individu/ha pada tingkat pohon. Hasil penelitian Siregar (2013), bahwa kerapatan vegetasi mangrove pada tingkat pertumbuhan pohon sebesar 77,97 individu/ha. Hal ini menunjukkan bahwa untuk saat ini terjadi peningkatan kerapatan individu mangrove di lokasi penelitian sebesar 633,13 individu/ha. Rapatnya populasi mangrove menyebabkan iklim mikro di lokasi penelitian lebih sejuk dan nyaman. Menurut Hayati, dkk. (2013), kondisi kerapatan tertinggi akan mempengaruhi iklim mikro dan menentukan kenyamanan lingkungan.

Tingginya kerapatan jenis Rhizopora apiculata dilokasi penelitian diduga bahwa kondisi lingkungan sangat sesuai untuk pertumbuhan. Menurut Iswahyudi dkk. (2019), di areal rehabilitasi mangrove yang terdapat di Kuala Langsa, dominan subtratnya mengandung lumpur lunak. Mirerra (2013) menyatakan substrat jenis lempung berpasir atau berlumpur merupakan substrat yang sangat cocok untuk tempat tumbuhnya jenis Rhizophora Sp dan Sonneratia alba .

Tabel 4 menunjukkan bahwa jenis mangrove yang dominan pada tiap tingkat perumbuhan semai, pancang dan pohon dilokasi penelitian adalah Rhizopora apiculata dengan INP masing-masing 200\%, 130\% dan 186\%. Jenis Rhizopora apiculata diperkirakan 
akan mendominasi populasi jenis mangrove di ekowisata Hutan Mangrove Kota Langsa pada masa yang akan mendatang.

Iswahyudi, dkk. (2020). menyatakan dominansi jenis Rhizopora Spp. diduga dipengaruhi oleh letak Kota Langsa yang berada di daerah teluk dan adanya Pulau Telaga Tujuh yang melindungi hutan mangrove di wilayah pesisir dari kerusakan yang disebabkan oleh hempasan gelombang, angin dan arus laut. Hal ini didukung oleh pernyataan Akbar, dkk. bahwa perbedaan kerapatan mangrove disebabkan karena letak stasiun dan kondisi pantai di daerah pengamatan, pengaruh gelombang dan angin serta memiliki topografi pantai. Susi, dkk. (2018) menjelaskan bahwa perbedaan kerapatan mangrove dipengaruhi oleh pola adaptasi serta keterlibatan manusia pada ekosistem mangrove. Andronicus. (2017) menambahkan bahwa perbedaan kerapatan mangrove sedikit juga dipengaruhi oleh tingkat ketahanan hidup mangrove, dimana masing-masing jenis memiliki kemampuan hidup yang berbeda.

\section{Ketebalan Mangrove}

Pengukuran ketebalan mangrove lokasi penelitian menggunakan Citra Satelit dengan menarik garis dari arah darat hingga ke arah laut. Berdasarkan pengukuran ketebalan mangrove dari Citra Satelit berkisar antara 121m - 165m. Transek 2 merupakan wilayah yang memiliki ketebalan mangrove paling tinggi $(165 \mathrm{~m})$ dan Transek 5 memiliki ketebalan mangrove terendah $(121 \mathrm{~m})$. Tebalnya mangrove di transek 2 karena wilayah ini merupakan kawasan hutan lindung mangrove yang pada saat ini dijadikan pusat pengembangan ekowisata hutan mangrove. Ketebalan mangrove disajikan pada (Tabel 5).

Di duga dengan banyaknya jenis mangrove pada tingkat pertumbuhan semai dan pancang yang mengalami suksesi berperan terhadap tingginya ketebalan mangrove di Transek 2. Sari (2015) menyatakan bahwa semakin tebal ekosistem mangrove maka biota yang berasosiasi dengan ekosistem mangrove semakin beranekaragam sehingga pengunjung dapat mengetahui jenis-jenis biota yang berasosiasi dengan hutan mangrove. Adanya perbedaan ketebalan mangrove dalam penelitian ini memiliki dampak terhadap aspek ekologis dari substrat, dan biota pesisir yang mana ketebalan mangrove yang tinggi akan mempengaruhi bahan organik dan kelimpahan macrobenthos dan plankton yang tinggi (Susi, dkk. 2018). Selain itu ketebalan mangrove juga dapat mempengaruhi salinitas air disekitarnya. Ketebalan mangrove berkisar antara 200-300 m memiliki kadar garam terendah (Setiawan, 2013)

Tabel 5. Ketebalan mangrove di lokasi penelitian

Table 5. Mangrove thickness at the study site

\begin{tabular}{c|c}
\hline Transek & Ketebalan Mangrove $(\mathrm{m})$ \\
\hline 1 & $145 \mathrm{~m}$ \\
3 & $165 \mathrm{~m}$ \\
4 & $159 \mathrm{~m}$ \\
5 & $128 \mathrm{~m}$ \\
6 & $121 \mathrm{~m}$ \\
\hline
\end{tabular}

Sumber: Data Primer (2020)

\section{Analisis Pasang Surut}

Pengukuran pasang surut di lokasi penelitian ini menggunakan data sekunder dari website https://tides4fishing.com/as/west-indonesia/langsa-bay terhitung mulai tanggal 1 Februari sampai dengan tanggal 29 Februari. Hasil perhitungan didapatkan bahwa nilai pasang tertinggi $(2,3 \mathrm{~m})$ dijumpai pada tanggal 11 dan pasang terendah $(0,7 \mathrm{~m})$ yang dijumpai pada tanggal 4. Tipe pasang surut di lokasi penelitian termasuk tipe pasang surut semi diurnal (pasang surut harian/harian ganda). Dalam waktu 24 jam terdapat 2 kali pasang 
dan 2 kali surut. Pasang pertama terjadi pukul 06.39 Waktu Indonesia Barat (WIB) dan pasang kedua terjadi pukul 18.41 Waktu Indonesia Barat (WIB). Pasang surut di lokasi penelitian di sajikan pada (Tabel 6).

Menurut Iswahyudi, dkk. (2019), tipe pasang surut All high tides di Hutan Mangrove Langsa sangat sesuai untuk pertumbuhan mangrove. Fluktuasi pasang surut juga menciptakan suatu ekosistem yang hanya sesuai untuk mangrove.

Tabel 6. Pasang surut di lokasi penelitian

Table 6. Tides at the study site

\begin{tabular}{|c|c|c|c|}
\hline Hari & $\begin{array}{c}\text { Pasang Surut } \\
\text { Tertinggi }\end{array}$ & $\begin{array}{c}\text { Pasang Surut } \\
\text { Terendah }\end{array}$ & $\begin{array}{c}\text { Hasil } \\
\text { ( Pasang Tertinggi - Pasang } \\
\text { Terendah) }\end{array}$ \\
\hline 1 & $1,8 \mathrm{~m}$ & $0,7 \mathrm{~m}$ & $1,1 \mathrm{~m}$ \\
\hline 2 & $1,7 \mathrm{~m}$ & $0,8 \mathrm{~m}$ & $0,9 \mathrm{~m}$ \\
\hline 3 & $1,7 \mathrm{~m}$ & $0,9 \mathrm{~m}$ & $0,8 \mathrm{~m}$ \\
\hline 4 & $1,7 \mathrm{~m}$ & $1,0 \mathrm{~m}$ & $0,7 \mathrm{~m}$ \\
\hline 5 & $1,8 \mathrm{~m}$ & $0,9 \mathrm{~m}$ & $0,9 \mathrm{~m}$ \\
\hline 6 & $2,0 \mathrm{~m}$ & $0,7 \mathrm{~m}$ & $1,3 \mathrm{~m}$ \\
\hline 7 & $2,1 \mathrm{~m}$ & $0,6 \mathrm{~m}$ & $1,5 \mathrm{~m}$ \\
\hline 8 & $2,2 \mathrm{~m}$ & $0,4 \mathrm{~m}$ & $1,8 \mathrm{~m}$ \\
\hline 9 & $1,9 \mathrm{~m}$ & $0,2 \mathrm{~m}$ & $1,7 \mathrm{~m}$ \\
\hline 10 & $2,3 \mathrm{~m}$ & $0,2 \mathrm{~m}$ & $2,1 \mathrm{~m}$ \\
\hline 11 & $2,4 \mathrm{~m}$ & $0,1 \mathrm{~m}$ & $2,3 \mathrm{~m}$ \\
\hline 12 & $2,3 \mathrm{~m}$ & $0,2 \mathrm{~m}$ & $2,1 \mathrm{~m}$ \\
\hline 13 & $2,2 \mathrm{~m}$ & $0,2 \mathrm{~m}$ & $2 \mathrm{~m}$ \\
\hline 14 & $2,0 \mathrm{~m}$ & $0,4 \mathrm{~m}$ & $1,6 \mathrm{~m}$ \\
\hline 15 & $2,0 \mathrm{~m}$ & $0,6 \mathrm{~m}$ & $1,4 \mathrm{~m}$ \\
\hline 16 & $1,9 \mathrm{~m}$ & $0,7 \mathrm{~m}$ & $1,2 \mathrm{~m}$ \\
\hline 17 & $1,8 \mathrm{~m}$ & $0,9 \mathrm{~m}$ & $0,9 \mathrm{~m}$ \\
\hline 18 & $1,8 \mathrm{~m}$ & $0,9 \mathrm{~m}$ & $0,9 \mathrm{~m}$ \\
\hline 19 & $1,8 \mathrm{~m}$ & $0,8 \mathrm{~m}$ & $1 \mathrm{~m}$ \\
\hline 20 & $0,7 \mathrm{~m}$ & $0,7 \mathrm{~m}$ & $1,2 \mathrm{~m}$ \\
\hline 21 & $2,0 \mathrm{~m}$ & $0,6 \mathrm{~m}$ & $1,4 \mathrm{~m}$ \\
\hline 22 & $2,0 \mathrm{~m}$ & $0,5 \mathrm{~m}$ & $1,5 \mathrm{~m}$ \\
\hline 23 & $1,6 \mathrm{~m}$ & $0,4 \mathrm{~m}$ & $1,5 \mathrm{~m}$ \\
\hline 24 & $2,1 \mathrm{~m}$ & $0,4 \mathrm{~m}$ & $1,7 \mathrm{~m}$ \\
\hline 25 & $2,1 \mathrm{~m}$ & $0,3 \mathrm{~m}$ & $1,8 \mathrm{~m}$ \\
\hline 26 & $2,1 \mathrm{~m}$ & $0,3 \mathrm{~m}$ & $1,8 \mathrm{~m}$ \\
\hline 27 & $2,1 \mathrm{~m}$ & $0,4 \mathrm{~m}$ & $1,7 \mathrm{~m}$ \\
\hline 28 & $2,0 \mathrm{~m}$ & $0,4 \mathrm{~m}$ & $1,6 \mathrm{~m}$ \\
\hline 29 & $2,0 \mathrm{~m}$ & $0,5 \mathrm{~m}$ & $1,5 \mathrm{~m}$ \\
\hline \multicolumn{3}{|c|}{ Jumlah } & $\begin{array}{l}41,9 \mathrm{~m} \\
1,44 \mathrm{~m}\end{array}$ \\
\hline
\end{tabular}

\section{Analisis Objek Biota}

Hasil penelitian didapatkan beragam jenis biota di kawasan mangrove Kuala Langsa. Jenis-jenis biota yang ditemukan dari hasil pengamatan secara langsung di lokasi penelitian disajikan pada Tabel 7. 
Tabel 7. Objek biota di lokasi penelitian

Table 7. Object of biota at the study site

\begin{tabular}{llll}
\hline No & Biota Mangrove & Nama Jenis & Keterangan \\
\hline 1 & Ikan & lkan Gelodok (Periopthalmus sp) & Mudah ditemukan \\
2 & Crustacea & $\begin{array}{l}\text { Kepiting Pemanjat Pohon (Episesarma sp) } \\
\text { Kepiting Laga (Uca sp) }\end{array}$ & $\begin{array}{l}\text { Mudah ditemukan } \\
\text { Mudah ditemukan }\end{array}$ \\
3 & Molluska & $\begin{array}{l}\text { Siput hijau (Nerita lineata) } \\
\text { Siput Timba (Nerita undata) }\end{array}$ & $\begin{array}{l}\text { Mudah ditemukan } \\
\text { Mudah ditemukan }\end{array}$ \\
& Monyet & Monyet ekor panjang (Macaca fascicularis) & Mudah ditemukan \\
\hline
\end{tabular}

Sumber: Data Primer (2020)

Dari Tabel 7 dapat dilihat bahwa terdapat 4 jenis biota yang dijumpai di lokasi penelitian, dimana jenis ini merupakan fauna khas ekosistem mangrove. Diduga banyaknya jenis mangrove dan ketebalan mangrove yang berkisar antara 121-165 m di lokasi penelitian mendukung terhadap berkembang biaknya biota di ekowisata hutan mangrove Kuala Langsa.

Adanya interaksi antar tumbuhan dan hewan pada hutan mangrove mempunyai arti penting bagi keseimbangan populasi, komunitas, dan proses yang terjadi pada tingkat ekosistem. Hal ini dikarenakan vegetasi mangrove merupakan komponen yang paling dominan dalam suatu ekosistem mangrove menurut Tomlinson, (1994).

Hasil penelitian Zurba, dkk. (2017) di Kuala Langsa terdapat 14 jenis objek biota yaitu; Belanak, Kuwe, Gelama, Kapasan, Kerang darah, Kepiting bakau, Udang putih, Udang windu, Udang galah, Kembung, Lemuru, Tembang, Teri, dan Tiram mutiara. Hasil penelitian Putriningtias, dkk (2019) menemukan 15 spesies kepiting di hutan mangrove Kuala Langsa yang termasuk ke dalam tujuh genus (lima famili) yang berbeda. Penelitian Majid, ddk (2014) di Kuala Langsa memiliki 5 jenis objek biota (monyet, ikan, kepiting dan moluska).

Biswas, dkk. (2008) menyatakan bahwa gelodok merupakan ikan penetap sejati yang siklus hidupnya berada di hutan mangrove. Krustasea merupakan hewan makrobentos yang hidup berasosiasi dengan mangrove. Secara ekologis daerah mangrove memiliki produktivitas yang tinggi untuk mendukung lingkungan di sekitarnya karena kaya akan nutrien dengan temperatur, $\mathrm{pH}$, oksigen, dan salinitas yang optimum serta kondisi perairan yang tenang sehingga sesuai untuk dijadikan sebagai habitat krustasea (Hogarth, 2007).

Garcia, dkk. (2000) menyatakan berbagai jenis fauna yang relatif kecil dan tergolong dalam invertebrata, seperti udang dan kepiting (krustasea), gastropoda dan juga bivalva (moluska), cacing (polikaeta) hidup di mangrove. Kebanyak invertebrata ini hidup menempel pada akar-akar mangrove, atau di lantai hutan mangrove. Sejumlah invertebrata tertinggal di dalam lubang-lubang di lantai hutan mangrove yang berlumpur. Melalui cara ini mereka terlindung dari perubahan temperatur dan faktor lingkungan lain akibat adanya pasang surut di daerah hutan mangrove.

\section{Analisis Kesesuaian Ekowisata Mangrove}

Indeks kesesuaian wisata (IKW) mangrove di lokasi penelitian disajikan pada Tabel 8. Berdasarkan hasil penelitan kesesuaian lokasi penelitian untuk dijadikan objek ekowisata mangrove IKWnya sebesar $60 \%$ yang termasuk dalam kategori $\mathrm{S}_{2}$ (sesuai), dengan faktor pembatas kerapatan mangrove dengan nilai 8 dengan kategori $S_{3}$ (sesuai bersyarat). 
Jurnal Belantara Vol. 3, No. 2, Agustus 2020 (176-188)

Tabel 8. Tingkat Kesesuaian Lahan

Table 8. Land Suitability Level

\begin{tabular}{|c|c|c|c|c|c|}
\hline No & Parameter & Hasil Penelitian & Bobot & Skor & $\begin{array}{l}\text { Bobot } x \\
\text { Skor }\end{array}$ \\
\hline 1. & Ketebalan mangrove & $145,66 \mathrm{~m}^{2}$ & 5 & 2 & 10 \\
\hline 2. & $\begin{array}{c}(\mathrm{m}) \\
\text { Kerapatan mangrove }\end{array}$ & $\begin{array}{c}7,11 \\
\text { pohon/100m }\end{array}$ & 4 & 2 & 8 \\
\hline 3. & $\left(\right.$ pohon $/ 100 \mathrm{~m}^{2}$ ) & & 4 & 3 & 12 \\
\hline 4. & Jenis mangrove & 2,66 & 3 & 3 & 9 \\
\hline 5. & $\begin{array}{l}\text { Pasang surut (m) } \\
\text { Objek biota }\end{array}$ & $\begin{array}{c}1,44 \mathrm{~m} \\
\text { Ikan, } \\
\text { kepiting,molusk } \\
\text { a }\end{array}$ & 3 & 3 & 9 \\
\hline \multicolumn{5}{|c|}{ Jum } & 48 \\
\hline \multirow{2}{*}{\multicolumn{5}{|c|}{ Nilai kesesuaian $=(48: 80) \times 100 \%$}} & $60 \%$ \\
\hline & & & & & S2 \\
\hline
\end{tabular}

Sumber: Data Primer (2020)

Berdasarkan hasil IKW maka Ekowisata Hutan Mangrove Kuala Langsa dapat dikembangkan sebagai objek wisata mangrove karena parameter-parameter yang dihitung telah memenuhi syarat dan layak untuk di kembangkan sebagai objek daya tarik wisata. Hasil ini tidak jauh berbeda dengan penelitian Majid, dkk. (2014) di kawasan hutan mangrove Kuala Langsa yang mendapatkan nilai IKW 53,77\% dengan kategori sesuai bersyarat (S2). Dapat dilihat secara umum potensi ekologi kawasan mangrove Kuala Langsa dapat dikembangkan sebagai kawasan ekowisata mangrove yang berkelanjutan. Namun upaya untuk meningkatkan nilai kesesuaian dikawasan ini masih perlu dilakukan.

Faktor pembatas utama untuk dapat dinaikkan IKW ekowisata mangrove Kuala Langsa adalah peningkatan kerapatan mangrove. Dari hasil penelitian, kerapatan mangrove di lokasi penelitian bernilai 8 yang termasuk kedalam kategori $\mathrm{S}_{3}$ (sesuai bersyarat). Hal yang perlu dilakukan adalah dengan melakukan rehabilitasi mangrove yang sesuai di lokasi tersebut, kemudian perlu dilakukan perawatan dan pemberian sanksi bagi masyarakat yang menebang. Karena kondisi ekosistem hutan mangrove yang rusak akan menghilangkan fungsi hutan mangrove. Program rehabilitasi hutan mangrove yang mulai dilakukan di Kota Langsa sejak tahun 2006 berdampak positif terhadap peningkatan kesejahteraan masyarakat yang mengantungkan hidupnya dari wilayah pesisir. Banyaknya famili dan jenis mangrove yang terdapat di ekosistem hutan mangrove Kota Langsa merupakan penyedia benih yang menjadi salah satu faktor pendukung untuk keberhasilan penanaman dalam rehabilitasi hutan mangrove di Kota Langsa. Sehingga dengan adanya jaminan kesediaan benih ini, maka benih bukan menjadi kendala utama dalam program reabilitasi yang akan dilakukan.

Menurut Davinsy, dkk. (2015) pengelolaan hutan mangrove berkelanjutan adalah kegiatan yang tepat dalam pemanfaatan lahan dan hasil hutan di daerah pesisir. Kegiatan ini merupakan langkah baik untuk mengurangi kerusakan ekosistem mangrove dan mempertahankannya. Keadaan dan faktor yang menunjang dalam pengelolaan hutan mangrove sangat perlu diketahui untuk pengembangan selanjutnya. Iswahyudi, dkk. (2019) menyatakan faktor yang perlu diperhatikan dalam pengembangan wisata berkelanjutan di kawasan hutan mangrove Kuala Langsa adalah; perbaikan dan penataan lingkungan, pemanfaatan sumberdaya alam secara berkelanjutan, sosial budaya masyarakat, integrasi wisata berkelanjutan ke dalam perencanaan dan dukungan perekonomian lokal. Sari, dkk. (2015) menambahkan bahwa dukungan, perhatian pemerintah, dan keterlibatan masyarakat sangat diperlukan dalam pengembangan sarana dan prasarana yang dapat menunjang pengembangan kegiatan ekowisata mangrove.

Ramadani dan Zidni, (2019) mengemukakan bahwa pemahaman masyarakat Kuala Langsa terhadap ekosistem mangrove cukup baik, sebagian besar masyarakat sudah mengetahui pengertian ekosistem mangrove secara umum dan pemanfaatannya, namun 
ada beberapa masyarakat yang belum mengetahuinya. Apabila hutan mangrove akan dikembangkan menjadi kawasan ekowisata, maka diperlukan adanya sosialisasi program atau penyuluhan konservasi secara kontinyu kepada masyarakat. Iswahyudi, dkk. (2019) menyatakan partisipasi aktif masyarakat untuk menjaga ekosistem dari aksi penebangan liar, konversi lahan menjadi tambak, atau bentuk lainnya merupakan salah satu kunci utuk menjaga kelestarian hutan mangrove Kota Langsa. Masyarakat yang berada di sekitar Ekowisata Hutan Mangrove perlu didorong untuk selalu terlibat dalam proses pengelolaan penjagaan dan perlindungan ekosistem mangrove yang ada agar terjaga kelestariannya sehingga dapat membantu meningkatkan ekonomi masyarakat (Tuwongkesong, dkk. 2018).

Hal lain yang perlu diperhatikan terhadap pengembangan Ekowisata Hutan Mangrove Kuala Langsa adalah keberlanjutan pengelolaannya. Adanya ekowisata Hutan Mangrove ini telah menjadikan Kota Langsa dikenal oleh masyarakat nasional maupun internasional dikarenakan oleh pemanfaatan hutan menjadi wisata dan memborong dua Piala sekaligus pada ajang penghargaan Anugrah Pesona Indonesia (API), Mangrove Forest Park Kota Langsa keluar sebagai Juara 1 Kategori Ekowisata Terpopuler sehingga Kota Langsa juga dinobatkan sebagai Most Favourit Tourism 2019 oleh Kementrian Pariwisata Republik Indonesia. Keberlanjutan pengelolaan ekosistem mangrove di Kota Langsa memiliki peran penting bagi kelestarian wilayah pesisir pantai timur Provinsi Aceh.

\section{KESIMPULAN}

Indeks Kesesuaian Wisata (IKW) Hutan Mangrove Kuala Langsa bernilai $55 \%$. Berdasarkan nilai tersebut, tingkat kesesuaian lahannya termasuk dalam kategori $S_{2}$ (sesuai). Dan faktor pembatas kerapatan mangrove dengan nilai (8) yang termasuk dalam kategori $\mathrm{K}_{3}$ (sesuai bersyarat).

Untuk menjaga agar keberlanjutan ekosistem hutan mangrove di Kota Langsa tetap terjaga maka harus dilakukan tatakelola yang baik dan benar. Adapun hal yang harus dilakukan untuk mewujudkan keinginan tersebut adalah dengan melakukan pengelolaan ekosistem hutan mangrove yang terpadu yang melibatkan seluruh stakeholder terkait dengan prinsip "Sinergitas Pentahelix" dimana disana harus ada peran aktif dari pihak pemerintah swasta, perguruan tinggi, masyarakat dan media.

\section{DAFTAR PUSTAKA}

Andronicus. 2017. Pengembangan Ekowisata Berbasis Masyarakat di Kawasan Pesisir Desa Bahoi, Kabupaten Minahasa Utara, Provinsi Sulawesi Utara. Institut Pertanian Bogor. Tesis. Sekolah Pascasarjana Institut Pertanian Bogor : Bogor.

Biswas, S. R., A. Mallik, J. Choudhury, and Nishat A. 2008. A unified framework for the restoration of Southeast Asian mangrove-bridging ecology, society and economics. Wetland Ecology and Management, 17:365-383.

Davinsy, R., A., Kustanti, dan R., Hilmanto. 2015. Kajian Pengelolaan Hutan di Desa Pulau Pahawang Kecamatan Marga Punduh Kabupaten Pesawaran. Jurnal Sylva Lestari. 3(3):95-106.

Garcia, S. M., and D. J. Staples. 2000. Sustainability reference systems and indicators for responsible marine capture fisheries: a review of concepts and elements for a set of guidelines: Marine \& Freshwater Research [Mar. Freshwat. Res.], 51(5):385-426.

Hafizi, R., Irma, D., Chitra, O. 2017. Produksi Serasah Hutan Mangrove di Kuala Langsa, Provinsi Aceh. Jurnal IImiah Mahasiswa Kelautan dan Perikanan Unsyiah. 2(4):556561.

Hayati, J., Santun, R.P. dan Siti, N. 2013. Pengembangan Ruang Terbuka Hijau dengan Pendekatan Kota Hijau di Kota Kandangan. Jurnal Tata Loka. 15 (4) : 306-316.

Hogarth, P. J. 2007. The Bioloogy of Mangroves and Seagrasses. New York: Oxford University Press Inc. 
Iswahyudi. 2019. Kebijakan Pengolaan Ekosistem Hutan Mangrove Berkelanjutan Kota Langsa. Disertasi. Sekolah Pascasarjana Institut Pertanian Bogor : Bogor.

Iswahyudi. 2020. Lingkungan Biofisik Hutan Mangrove Kota Langsa, Aceh. Jurnal of Natural Resources and Environmental Management. 10(1) : 98-110.

Kusmana, C. 1997. Ekologi dan Sumberdaya Ekosistem Mangrove, Makalah Pelatihan Pengelolaan Hutan Mangrove Lestari Angkatan I PKSPL. Institut Pertanian Bogor. Bogor.

Kusmana, C., Wilarso S., Iwan, H., Pamoengkas, P., Wibowo, C., Tiryana, T., Triswanto, A., Hamzah, Y. 2005. Teknik Rehabilitasi Mangrove. Bogor : Fakultas kehutanan Institut Pertanian Bogor : Bogor.

Latupapua, Y., T., Ronny, L., Fitrah D. S. F. 2019. Analisis Kesesuaian Kawasan Mangrove sebagai Objek Daya Tarik Ekowisata di Desa Siahoni, Kabupaten Buru Utara Timur, Propinsi Maluku. Jurnal Sylva Lestari. 7(3):267-276.

Majid, A., B., Patana, P., Lesmana, L. 2014. Studi Potensi Ekowisata di Kuala Langsa Provinsi Aceh. Aquacoastmarine. 3(2):44-54.

Mirerra, O.D, J. Ochiewo, F. Munyi, and T. Muriuki. 2013. Heredity or traditional knowledge: Fishing tactics and dynamics of artisanal mangrove crab (Scylla serrata) fishery. Ocean andCoastal Management, (84):119-129.

Nurlailita. 2015. Evaluasi Kesesuaian Lahan dan Strategi Rehabilitasi Hutan Mangrove Kecamatan Birem Bayeun dan Kecamatan Rantau Selamat Kabupaten Aceh Timur. Tesis. Sekolah Pascasarjana Institut Pertanian Bogor : Bogor.

Putriningtias, A., Faisal, T., M., Komariyah, S., Bahri, S., Akbar, H. 2019. Keanekaragaman Jenis Kepiting di Ekosistem Hutan Mangrove Kuala Langsa, Kota Langsa, Aceh. Jurnal Biologi Tropis. 19(1):101 - 107.

Rahim, S., D., W., K., Baderan. 2017. Hutan Mangrove dan Pemanfaatannya. Yogyakarta : Budi Utama. Yogyakarta.

Ramadani, R., Zidni I., N., M.Si. 2019. Pengembangan Potensi Ekowisata Hutan Mangrove di Desa Kuala Langsa Kecamatan Langsa Barat Kota Langsa Aceh. Jurnal Biologica samudra. 1(1);041-055.

Roza, M., Dedi, H., dan Triyatno. 2018. Strategi Pengembangan Ekowisata Mangrove di Desa Rawa Mekar Jaya Kecamatan Sungai Apit Kabupaten Siak Provinsi Riau. Jurnal Buana. 2(4):2615 - 2630.

Sadik, M., Muhiddin, A. H., dan Ukkas, M. 2017. Kesesuaian Ekowisata Mangrove Ditinjau Dari Aspek Biogofisik Kawasan Pantai Gonda Di Desa Laliko Kecamatan Campalangian Kabupaten Polewali Mandar. Jurnal IImu Kelautan SPERMONDE Universitas Hasanuddin 2(2):25-33

Sari, I. P., Defri, Y., Evi, S. 2015. Analisis Kelayakan Ekosistem Mangrove Sebagai Objek Ekowisata di Desa Teluk Pambang Kecamatan Bantan Kabupaten Bengkalis. Jom Faperta.Vol. 2 No 1

Setiawan, H. 2013. Status Ekologi Hutan Mangrove Pada Berbagai Tingkat Ketebalan. Jurnal Penelitian Kehutanan Wallacea. 2(2):104-120.

Siregar, D., S. 2013 . Inventarisasi Tingkat Kerusakan dan Cadangan Karbon di Hutan Lindung Mangrove Kuala Langsa Kota Langsa-Aceh. Tesis. Program Studi Agroteknologi Universitas Sumatera Utara : Medan.

Susi, S., Adi, W., dan Sari, S. P. 2018 Potensi Kesesuaian Mangrove Sebagai Daerah Ekowisata Di Susun Tanjung Tedung Sungai Selan Bangka Tengah. Akuatik: Jurnal Sumberdaya Perairan 12(1):65-73. SOI:10.33019/akuatik.vl2i.693.

Tomlinson, P., B. 1994. The Botany of Mangroves. Cambridge (UK): Cambridge University Press.

Tuwongkesong, H., Mandagi, S., V., Schaduw, J., N. 2018. Kajian ekologis ekosistem mangrove untuk ekowisata di Bahowo Kota Manado. Majalah Geografi Indonesia. 32(2):177-183.

Zurba, N. 2017. Pengelolaan Potensi Sumberdaya Ekosistem Mangrove di Kuala Langsa, Aceh. Tesis. Sekolah Pascasarjana Institut Pertanian Bogor : Bogor. 